\title{
Hepatitis B Vaccination Induced TNF- $\alpha$ - and IL-2-Producing T Cell Responses in HIV - Healthy Individuals Higher than in HIV+ Individuals Who Received the Same Vaccination Regimen
}

\author{
Kriangkrai Chawansuntati $\mathbb{D}^{1}{ }^{1}$ Kanokporn Chaiklang, ${ }^{1,2}$ Romanee Chaiwarith, ${ }^{2}$ \\ Jutarat Praparattanapan $\left(\mathbb{1},{ }^{2}\right.$ Khuanchai Supparatpinyo, ${ }^{1,2}$ and Jiraprapa Wipasa $\left(^{1}\right.$ \\ ${ }^{1}$ Research Institutes for Health Sciences, Chiang Mai University, Chiang Mai 50202, Thailand \\ ${ }^{2}$ Department of Medicine, Faculty of Medicine, Chiang Mai University, Chiang Mai 50202, Thailand \\ Correspondence should be addressed to Jiraprapa Wipasa; jiraprapa.wipasa@cmu.ac.th
}

Received 8 August 2017; Accepted 28 December 2017; Published 27 February 2018

Academic Editor: Baohui Xu

Copyright (c) 2018 Kriangkrai Chawansuntati et al. This is an open access article distributed under the Creative Commons Attribution License, which permits unrestricted use, distribution, and reproduction in any medium, provided the original work is properly cited.

\begin{abstract}
We investigated cytokine production and expression of degranulation marker CD107a after different strategies of hepatitis B virus (HBV) vaccination in human immunodeficiency virus-infected individuals, which were three doses of $20 \mu \mathrm{g}$ (standard dose group), four doses of $20 \mu \mathrm{g}$ (four doses group), or four doses of $40 \mu \mathrm{g}$ (four double doses group), compared to standard dose vaccination in healthy controls. PBMCs collected at different time points were stimulated in vitro with recombinant hepatitis B surface antigen and analyzed by flow cytometry. There was an increase in TNF- $\alpha$ production of total and memory CD4+ T cells at 7 months after vaccination in healthy controls compared to the HIV+ group, which received the same standard vaccination regimen. An increase in the IL-2-producing memory CD4+ T cells in the healthy control group was also observed at 7 months after vaccination. No differences were observed between the healthy controls and both groups of four doses at any time point of study. These results suggest that the standard HBV vaccination schedule might induce better production of TNF- $\alpha$ and IL-2 from CD4+ T cells in healthy individuals. Modification of HBV vaccination schedule by increasing the frequency and/or dosage may improve the CMI response in HIV-infected individuals. This trial is registered with NCT1289106.
\end{abstract}

\section{Introduction}

Hepatitis B virus (HBV), which causes hepatitis B liver diseases, is one of the most serious infectious viruses. As HBV and human immunodeficiency virus (HIV) share similar routes of transmission, coinfection with $\mathrm{HBV}$ is more common in HIV-infected (HIV+) individuals than in the general population [1-3]. The reported prevalence of $\mathrm{HBV} /$ HIV coinfection ranges between $8.7 \%$ and $10.4 \%$ in Asia, including Thailand $[4,5]$. Progression of HBV-related liver diseases in HIV+ individuals is more accelerated than in patients with chronic HBV infection alone $[6,7]$. Therefore, prevention of $\mathrm{HBV}$ infection by vaccination in HIV+ individuals is strongly recommended [8-10]. However, the efficacy of HBV vaccine to induce protective antibody levels in HIV+ individuals is low compared to that in the HIVgeneral population [11-16]. Several studies have reported improvement in the response to $\mathrm{HBV}$ vaccine by using higher doses $[17,18]$, increasing the frequencies $[18,19]$, and increasing both the doses and the frequencies $[11,18,20]$.

Besides antibodies that play a crucial role in protection against $\mathrm{HBV}$ infection, $\mathrm{T}$ cell immune response is considered necessary for sufficient control and clearance of HBV [21]. $\mathrm{CD} 4+\mathrm{T}$ cell response in the acute phase of self-limiting infection patients is significantly more frequent, strong, and multispecific than that observed in chronic patients [22-24]. These CD4+ T cells have a preferential Th-1 profile, which is specific to multiple epitopes of $\mathrm{HBV}$ antigens [24-27]. CD8+ T cells serve a dual function in HBV control, which is the elimination of $\mathrm{HBV}$-infected cells via their 
cytotoxicity and antiviral activity by secreting antiviral cytokines such as interferons (IFNs) and tumor necrosis factor- (TNF-) $\alpha$ without cytolytic activity [28-30].

In contrast to widely studied serological response, CMI response to $\mathrm{HBV}$ vaccination is less well understood, especially in $\mathrm{HIV}+$ populations. The precise role of $\mathrm{CMI}$ responses in protection against the $\mathrm{HBV}$ infection is not yet known. Nevertheless, vaccination with $\mathrm{HBV}$ vaccine induced long-lived CMI, which can be boosted by revaccination despite the absence of protective levels of antibodies $[31,32]$. This study aimed to investigate the cytokine production and expression of the degranulation marker (CD107a) of $\mathrm{T}$ cells in response to in vitro recombinant hepatitis $\mathrm{B}$ surface antigen ( $\mathrm{HBsAg}$ ) stimulation in $\mathrm{HIV}+$ individuals who received different strategies of $\mathrm{HBV}$ vaccination compared to standard vaccination in healthy controls. The results from this study may provide elementary knowledge for addressing important issues for development of an $\mathrm{HBV}$ vaccine strategy, especially for $\mathrm{HIV}+$ populations.

\section{Materials and Methods}

2.1. Study Population. Participants in this study were the same individuals as those in the study on immunogenicity and safety of different regimens of hepatitis $B$ vaccination in HIV-infected adults reported previously [18]. The individuals consisted of $132 \mathrm{HIV}+$ and $40 \mathrm{HIV}$ - healthy individuals over eighteen years old, who were seronegative for HBsAg, antibody to hepatitis B surface antigen (anti-HBs), antibody to hepatitis B core antigen (anti-HBc), and antibody to hepatitis $\mathrm{C}$ virus (anti-HCV), and without a history of previous HBV vaccination; they were enrolled at Maharaj Nakorn Chiang Mai Hospital, Chiang Mai, Thailand, between February 2011 and May 2012. HIV+ individuals were eligible to participate if they had absolute number of CD4+ T cells of more than 200 cells $/ \mathrm{mm}^{3}$, had HIV viral load of less than 50 copies $/ \mathrm{mL}$, and received antiretroviral therapy (ART). Exclusion criteria included being pregnant or breastfeeding; having a history of hypersensitivity to any component of the vaccine or other immunocompromised conditions besides HIV, renal insufficiency, or decompensated cirrhosis; and receiving chemotherapy or radiation for active malignancy treatment or immunosuppressiveness, or immunomodulating treatment in the last six months before the screening visit. Healthy controls were confirmed HIV negative by using a rapid immunochromatographic screening assay (Pacific Biotech, Thailand).

This study was approved by the ethics committees of the Research Institute for Health Sciences and the Faculty of Medicine, Chiang Mai University, Thailand. All participants were informed about the details of the study and given time to put across any enquiries they had before enrolling in the study consentingly. The authors confirm that all related trials for this intervention were registered to the ClinicalTrials.gov (NCT1289106) on February 1, 2011.

2.2. Study Procedure. HIV+ individuals were randomized $(1: 1: 1)$ by blocks of six into three groups (44 subjects per group). They were given different doses and frequencies of
Hepavax-Gene ${ }^{\circledR}$ vaccine (Berna Biotech Korea Corp, South Korea) containing noninfectious inactivated recombinant HBsAg. Group 1 was defined as the "standard dose group": the subjects were vaccinated with $20 \mu \mathrm{g}$ of $\mathrm{HBV}$ vaccine at days 0 and 28 and month 6. Group 2 was the "four doses group": the subjects were vaccinated with $20 \mu \mathrm{g}$ of $\mathrm{HBV}$ vaccine at days 0 and 28 and months 2 and 6. Group 3 was the "four double doses group": the subjects were vaccinated with $40 \mu \mathrm{g}$ of $\mathrm{HBV}$ vaccine at days 0 and 28 and months 2 and 6 . The healthy individuals were vaccinated with the standard regimen similar to that of the HIV+ participants in group 1. Venous blood was collected from all the participants at day 0 (D0) (as baseline), day 7 (D7), day 28 (D28), month 2 (2m) (only for the four doses and four double doses groups), month $6(6 \mathrm{~m})$, month $7(7 \mathrm{~m})$, and month $12(12 \mathrm{~m})$. The CONSORT diagram of participants is shown in Figure 1.

Baseline demographic and clinical characteristics of HIV+ participants have been reported previously [18]. Briefly, the mean age of the HIV+ standard dose group, the HIV+ four doses group, the HIV+ four double doses group, and the HIV - healthy control group was $41.0 \pm 6.3$, $42.2 \pm 7.6,41.0 \pm 6.2$, and 33.2 \pm 9.5 , respectively. The medians of the absolute CD4+ T cell counts of the HIV+ standard dose group, the HIV+ four doses group, and the HIV+ four double doses group were 400 (interquartile range (IQR) 314-558) cells/mL, 544 (IQR 416-731) cells/mL, and 544 (IQR 410-642) cells/mL, respectively. At month 7 after vaccination, the percentages of seroresponders (anti$\mathrm{HBs} \geq 10 \mathrm{mIU} / \mathrm{mL}$ ) were $88.6 \%$ in the $\mathrm{HIV}+$ standard dose group, $93.2 \%$ in the HIV+ four doses group, $95.4 \%$ in the HIV+ four double doses group, and $94.7 \%$ in the HIVhealthy control group.

\subsection{Isolation of Peripheral Blood Mononuclear Cells. PBMCs} were isolated by gradient centrifugation, as previously described [33]. Participants' whole blood was diluted with plain RPMI 1640 medium (Life Technologies, USA), and Ficoll-Hypaque solution (Biochrom, Germany) was layered under the diluted blood. After centrifugation, the PBMC enriched interface was collected, and the residual red blood cells were lysed using ammonium-chloride-potassium lysis buffer. The PBMCs were resuspended in fetal bovine serum (FBS; Biochrom, Germany) containing 10\% dimethyl sulfoxide (DMSO; Sigma-Aldrich, USA) and stored in liquid nitrogen until use.

2.4. Cell Stimulation and Determination of CytokineProducing T Cells. Cryopreserved PBMCs from each participant at all time points were investigated simultaneously. After overnight rest of thawed PBMC, the cells were cultured in the presence of anti-CD107a-PE in complete RPMI containing $2 \mu \mathrm{g} / \mathrm{mL}$ of recombinant HBsAg (MyBioSource, USA) and $5 \mu \mathrm{g} / \mathrm{mL}$ of PHA (Sigma-Aldrich, USA) as the positive stimulation control or complete media alone as the unstimulated control at $37^{\circ} \mathrm{C}$ in a $5 \% \mathrm{CO}_{2}$ incubator for $16-18 \mathrm{hr}$.

Cytokine-producing $\mathrm{T}$ cells analysis was performed as described previously [34]. Briefly, the overnight culture was further incubated with $5 \mu \mathrm{g} / \mathrm{mL}$ of brefeldin $\mathrm{A}$ and $1 \mu \mathrm{M}$ of monensin (Sigma-Aldrich, USA) for $4 \mathrm{hr}$. Then, 


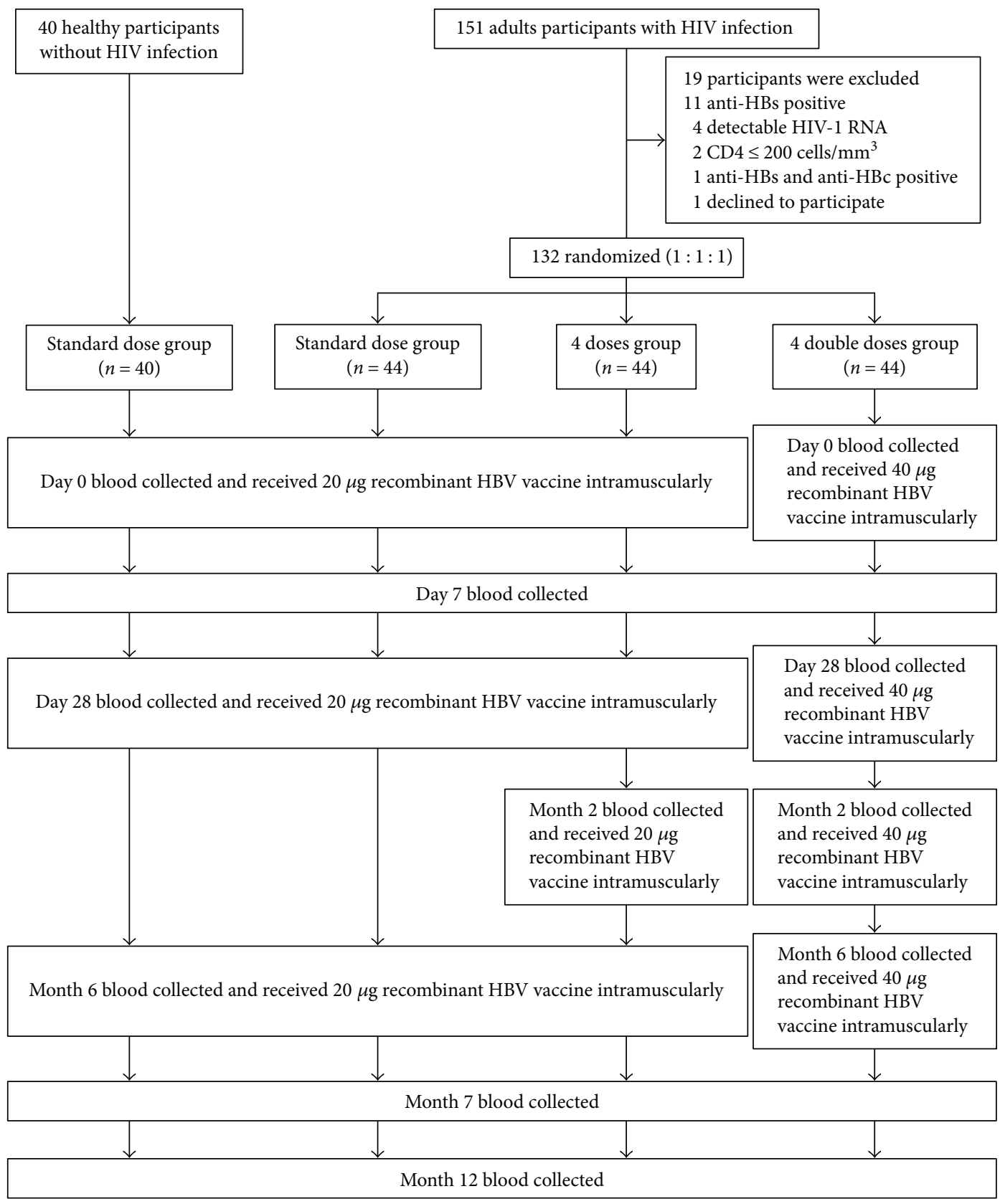

FIGURE 1: CONSORT diagram of participants in this study.

the cells were stained with anti-CD8-PE Alexa Fluor 610 (Life Technologies, USA), and anti-CD4-APC/Cy7 and anti-CD45RO-Pacific Blue (BioLegend, USA). After fixation and permeabilization, intracellular staining was performed by incubating the cells with anti-CD3-Krome Orange (Beckman Coulter, USA), and with anti-TNF- $\alpha$-FITC, anti-IFN- $\gamma$-PerCP/Cy5.5, anti-IL-2-PE/Cy7, and anti-IL-10APC (BioLegend, USA). At least 100,000 lymphocytes were collected for each sample by using Cyan ADP 9-color flow cytometer (Beckman Coulter, USA). Flow cytometric analysis of cytokine-producing or degranulation maker CD107aexpressing $\mathrm{T}$ cells was performed by using Kaluza software (Beckman Coulter, USA).
2.5. Flow Cytometric Analysis. To assess cytokine production and CD107a expression by CD4+ and CD8+ T cells, T cells were identified from the $\mathrm{CD} 3+$ population by Boolean combination gating of forward scatter (FSC) versus side scatter (SSC) plot and CD3 versus SSC plot. Single-positive $\mathrm{CD} 4+$ and $\mathrm{CD} 8+$ populations were then identified within the CD3+ gate. To evaluate cytokine production and degranulation marker of CD4+ or CD8+ populations, IFN- $\gamma$, IL-2, IL-10, and CD107a were plotted against TNF- $\alpha$.

To assess cytokine production and CD107a expression by memory T cells, CD45RO was used as memory marker of T cells (Figures 2(a)-2(d)). Lymphocyte population was initially determined from plot of FSC versus SSC (Figure 2(a)). 


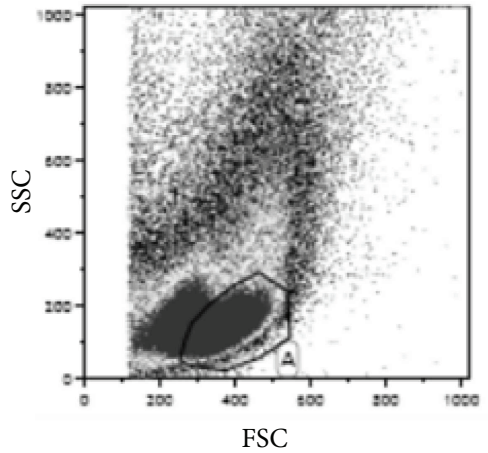

(a)
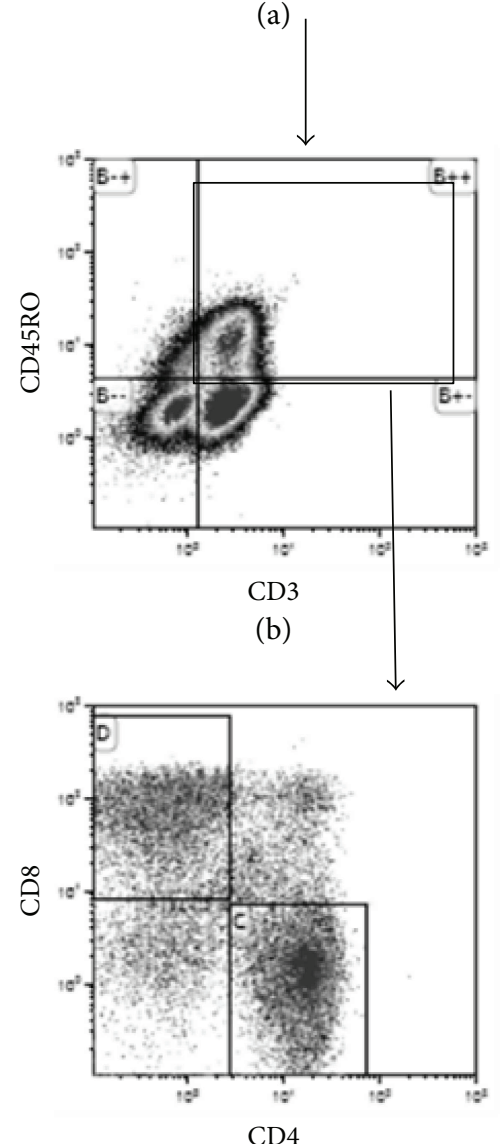

(c)
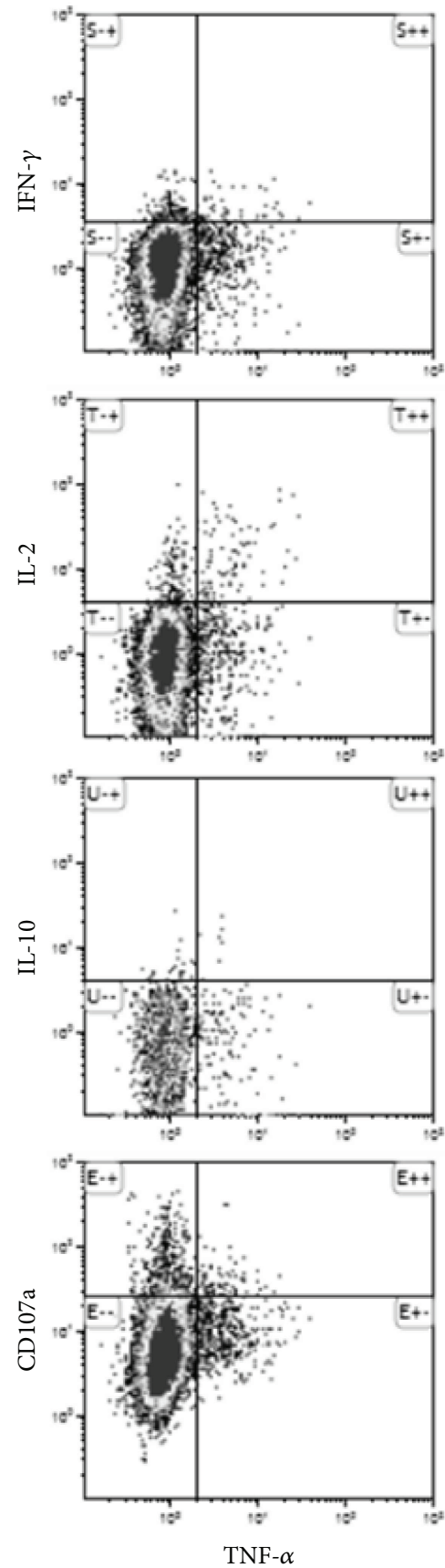

(d)

FIGURE 2: Gating strategies for flow cytometric analysis. The gating strategy used to determine cytokine-producing and CD107a-expressing memory $\mathrm{T}$ cells $(\mathrm{a}-\mathrm{c})$. Memory $\mathrm{T}$ cells were identified from lymphocyte population (a) and double positive population of CD3 versus CD45RO plot (b). Memory CD4+ or CD8+ T cells were then identified from CD4 versus CD8 plot (c). Cytokine production and expression of surface CD107a of CD45RO+CD4+ or CD8+ memory T cell subpopulation were then evaluated (d).

Memory $\mathrm{T}$ cells $(\mathrm{CD} 3+\mathrm{CD} 45 \mathrm{RO}+)$ were then gated from CD3 versus CD45RO plot (Figure 2(b)). Single-positive $\mathrm{CD} 4+$ or $\mathrm{CD} 8+$ populations were then identified from CD4 versus CD8 plot (Figure 2(c)). Expression of intracellular cytokines or surface CD107a of memory $\mathrm{T}$ cells were identified from plots of IFN- $\gamma$, IL-2, IL-10, and CD107a against TNF- $\alpha$ (Figure 2(d)).
2.6. Statistical Analysis. All data sets were assessed for normal distribution by using D'Agostino and Pearson omnibus normality test. Paired $t$-test or Wilcoxon signed-rank test and independent $t$-test or Mann-Whitney $U$ test were then used depending on data distribution of matched or independent data, respectively. A comparison between study groups was assessed by using Kruskal-Wallis test. Statistical analysis 
was done by using GraphPad Prism Version 5 software (GraphPad Software, USA). A $p$ value of less than 0.05 was considered statistically significant.

\section{Results}

3.1. Cytokine Production and CD107a Expression of CD4+ and $C D 8+T$ Cells. Vaccination and blood collection schedules carried out in this study are presented as a CONSORT diagram in Figure 1. Peripheral blood mononuclear cells (PBMCs) were isolated for determination of immunological responses. Cytokine-producing and CD107a-expressing $\mathrm{CD} 4+$ or $\mathrm{CD} 8+\mathrm{T}$ cells were identified, as described in Materials and Methods. The results are presented as fold increases of the percentages of $\mathrm{CD} 4+$ or $\mathrm{CD} 8+\mathrm{T}$ cells that produced TNF- $\alpha$, IFN- $\gamma$, IL-2, and IL-10 or expressed $\mathrm{CD} 107 \mathrm{a}$ in response to in vitro recombinant HBsAg stimulation over the medium alone. The fold increases of the percentages of cytokine-producing and CD107a-expressing $\mathrm{CD} 4+$ and $\mathrm{CD} 8+\mathrm{T}$ cells in each of the study groups were compared between D0 as the baseline, D7, 1m, 2m (only for the four doses and four double doses groups), $6 \mathrm{~m}$, $7 \mathrm{~m}$, and $12 \mathrm{~m}$ after vaccination. In the healthy control group, only the median fold increase of TNF- $\alpha$-producing $\mathrm{CD} 4+\mathrm{T}$ cells in response to recombinant HBsAg stimulation in vitro at $7 \mathrm{~m}$ was statistically significantly higher than that at D0 $(p=0.02), \mathrm{D} 7(p=0.005), 6 \mathrm{~m}(p=0.033)$, and $12 \mathrm{~m}(p=0.019)$ after vaccination (data not shown). No differences in the median fold increase of the TNF- $\alpha$ producing CD8+ T cells and the IFN- $\gamma$-, IL-2-, and IL-10producing and CD107a-expressing CD4+ and CD8+ T cells between all the time points of the study were observed in this study group. There were no statistical differences between the median fold increases of the cytokine-producing and CD107a-expressing CD4+ and CD8+ $\mathrm{T}$ cells between the time points in all the three HIV+ study groups. In response to positive control phytohaemagglutinin (PHA) stimulation, strong cytokine production and CD107a expression were observed in all the participants regardless of their HIV status. There were no differences in these responses between the groups at all the time points of the study (data not shown).

3.2. Cytokine Production and CD107a Expression of CD4 and CD8 Memory T Cells. To evaluate cytokine-producing and CD107a-expressing memory $\mathrm{T}$ cell populations, CD45RO marker was used in the gating strategy, as described in Materials and Methods (Figures 2(a)-2(d)). The percentages of memory CD4+ or CD8+ T cells that produced TNF- $\alpha$, IFN- $\gamma$, IL-2, and IL-10, or expressed CD107a in response to in vitro stimulation with HBsAg or medium alone, are presented in Supplementary Table (available here). The median fold increase of the percentages of cytokine-producing and CD107a-expressing memory CD4+ and CD8+ T cells between the study groups was compared between D0 as the baseline, D7, 1m, $2 \mathrm{~m}$ (only for the four doses and four double doses groups), $6 \mathrm{~m}, 7 \mathrm{~m}$, and $12 \mathrm{~m}$ after vaccination. In the healthy control group (Figure 3), there were no statistical differences in the IFN- $\gamma$ - (Figure 3(b)) and IL-10-producing
(Figure 3(d)) or the CD107a-expressing (Figure 3(e)) memory $\mathrm{CD} 4+\mathrm{T}$ cells between all the time points of the study. However, the fold increases of the TNF- $\alpha$-producing memory CD4+ T cells (Figure $3(\mathrm{a})$ ) at $7 \mathrm{~m}$ after vaccination were significantly higher than those at prevaccination (D0, $p=0.042)$ and $12 \mathrm{~m}(p=0.02)$. The fold increases of the IL-2-producing memory CD4+ T cells (Figure 3(c)) at $7 \mathrm{~m}$ after vaccination were statistically significantly higher than those at D0 $(p=0.008), \mathrm{D} 7(p=0.007), 1 \mathrm{~m}(p=0.027)$, and $6 \mathrm{~m}(p=0.009)$. In contrast to memory CD4+ T cells, no differences in the fold increase of cytokine production and expression of CD107a of memory CD8+ T cells (Figures 3(f)-3(j)) were observed at all the time points of the study. In all the study groups of the HIV+ individuals, there were no statistical differences in the median fold increases of cytokine production and expression of CD107a of the memory CD4+ and CD8+ T cells at any time point of the study (data not shown).

When compared between four groups at D0 and $7 \mathrm{~m}$, statistical analysis of the fold increases of cytokine-producing and CD107a-expressing memory CD4+ (Figures 4(a)-4(e)) and CD8+ (Figures 4(f)-4(j)) T cells did not demonstrate statistically significant differences between the groups. The data were further analyzed by comparing the median fold increases between the study groups. Based on the definition of responsiveness to HBV vaccination, which is generation of anti-HBsAg antibodies $\geq 10 \mathrm{IU} / \mathrm{mL}$ (levels presumptive for seroprotection) at 1 month after three doses of vaccination [35], and since we observed an increase in the cytokine-producing $\mathrm{T}$ cells at $7 \mathrm{~m}$ after initial vaccination, as described above, the comparisons of the cytokineproducing and CD107a-expressing $\mathrm{T}$ cells between the study groups at the baseline and at $7 \mathrm{~m}$ after first vaccination were selected. There were no statistical differences in the median fold increases of all the cytokine-producing and CD107a-expressing memory CD4+ (Figure 5(a)) and CD8+ (Figure 5(b)) T cells between the HBV vaccine serological nonresponders and the responders compared at D0 and $7 \mathrm{~m}$ after vaccination. In response to positive control phytohaemagglutinin (PHA) stimulation, strong cytokine production and CD107a expression were observed in all the participants regardless of their HIV status. There were no differences in these responses between the groups at all the time points of the study (Figure 6).

\section{Discussion}

The effectiveness of HBV vaccination in HIV+ individuals has been broadly investigated in relation to humoral immune response. In contrast, the knowledge of cellular immune responses is much less well understood. This study focused on the cytokine production and expression of the degranulation marker of CD4+ and CD8+ T cells in response to in vitro recombination HBsAg stimulation in HIV+ individuals following different vaccination regimes as compared to those in healthy donors.

We found no statistical differences in the frequencies of cytokine production and CD107a expression of total or memory CD4+ or CD8+ $\mathrm{T}$ cells during the 12 months of 


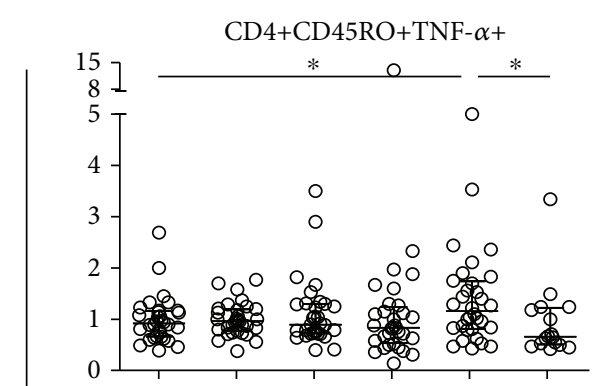

(a)

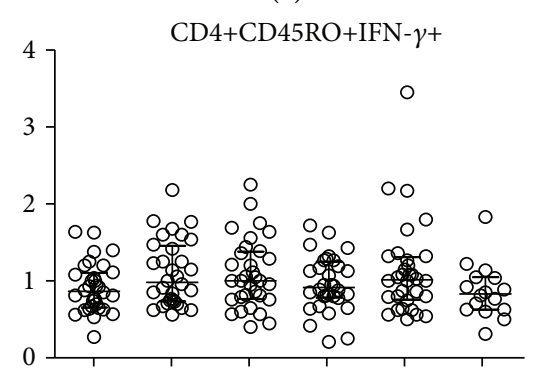

(b)

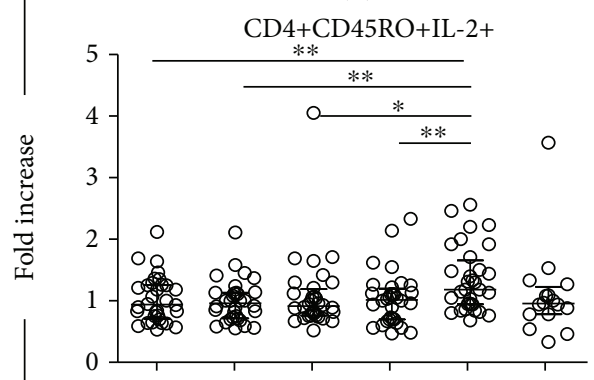

(c)

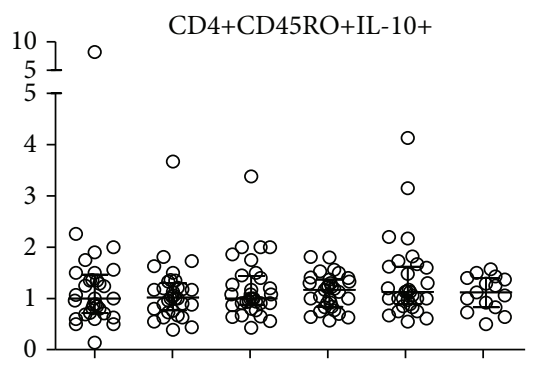

(d)

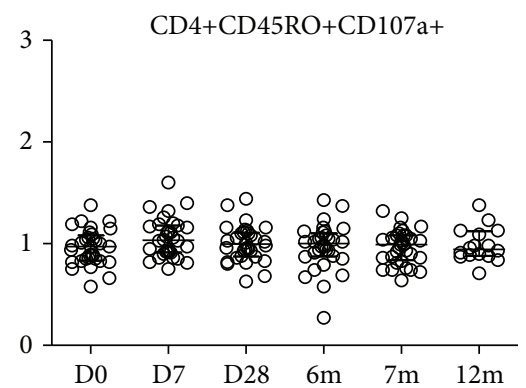

(e)

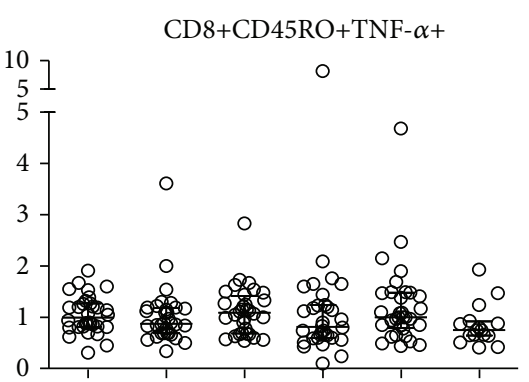

(f)

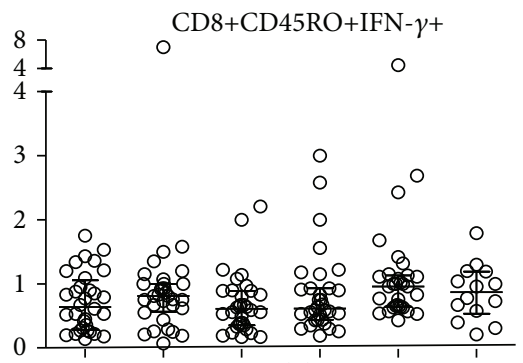

(g)

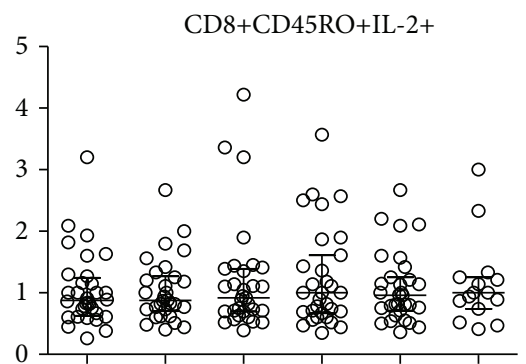

(h)

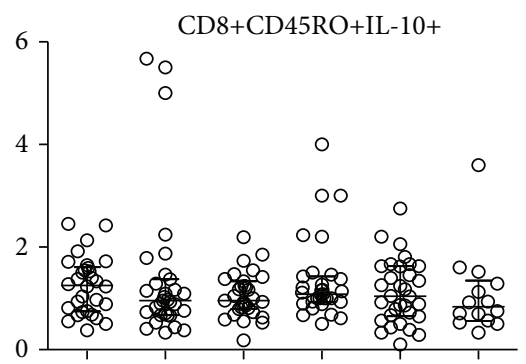

(i)

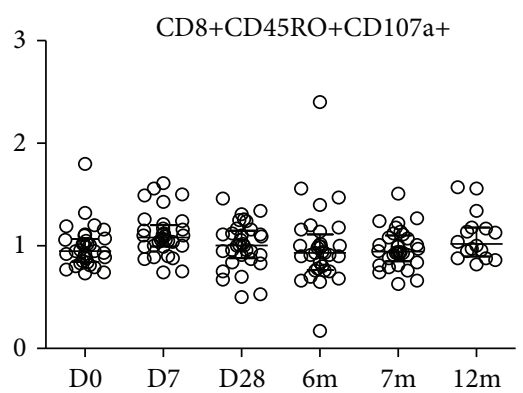

(j)

FIgURE 3: Fold increases in cytokine-producing and CD107a-expressing memory T cells in healthy control individuals. Fold increases in TNF- $\alpha$, IFN- $\gamma$, IL-2, and IL-10 cytokine production, and CD107a expression, by memory CD4+ (a-e) and CD $8+(\mathrm{f}-\mathrm{j}) \mathrm{T}$ cells in response to recombinant HBsAg by HIV- healthy individuals who were vaccinated with the standard dose regimen, compared before in vivo vaccination on day 0 (D0), and at day 7 (D7), day 28 (D28), month $6(6 \mathrm{~m})$, month 7 (7m), and month 12 (12m) after vaccination. Medians are represented by thick, wide horizontal bars; $25-75 \%$ interquartile ranges are represented by thin, narrow bars. All $p$ values $<0.05$ were considered statistically significant. " $*$ " and “**” stand for $p<0.05$ and $p<0.01$, respectively. 


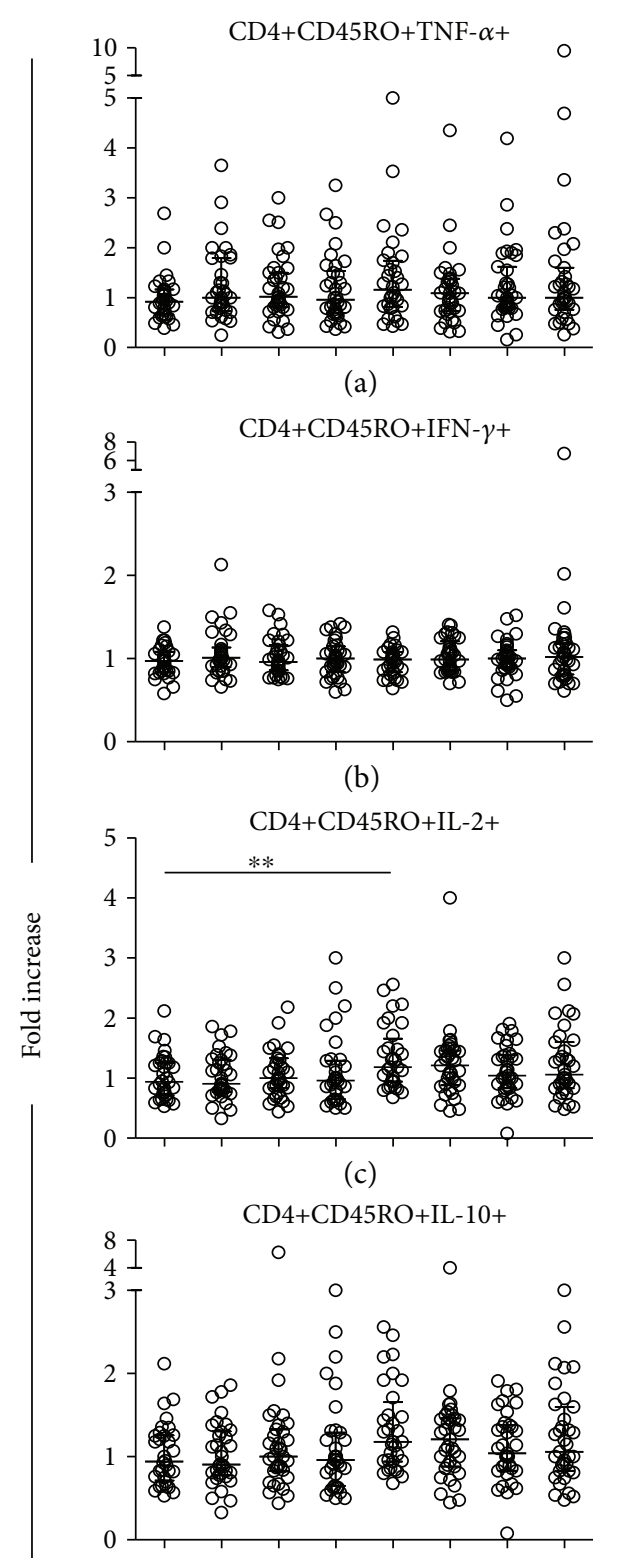

(d)

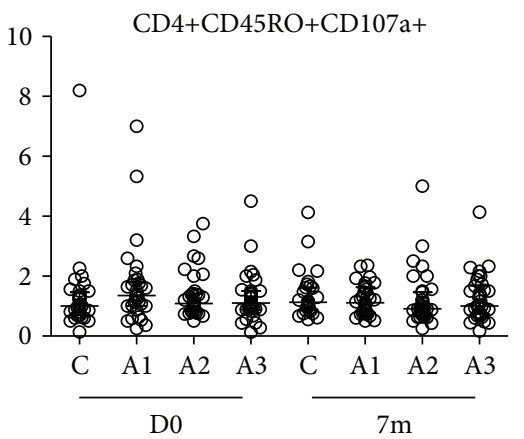

(e)

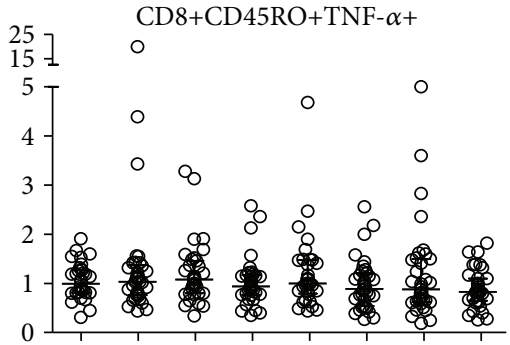

(f)

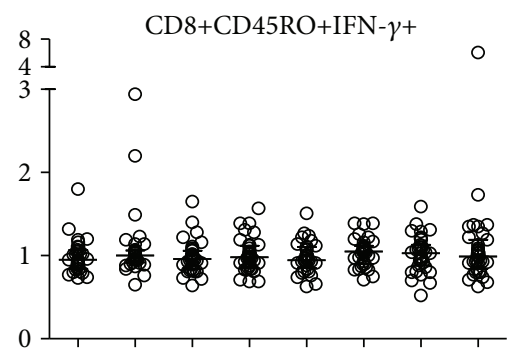

(g)

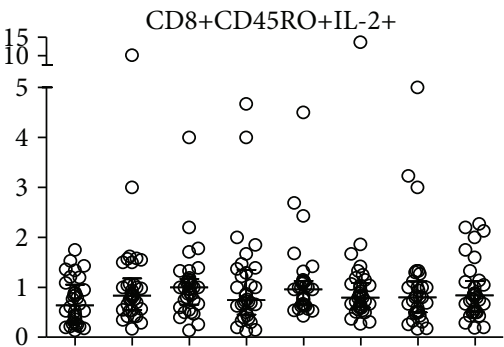

(h)

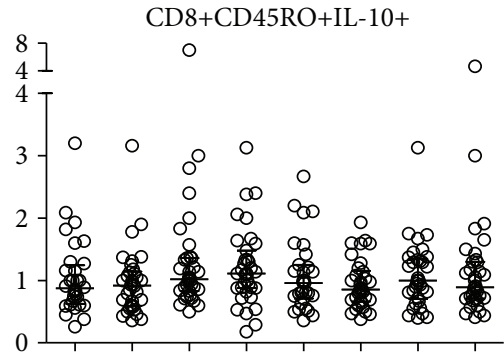

(i)

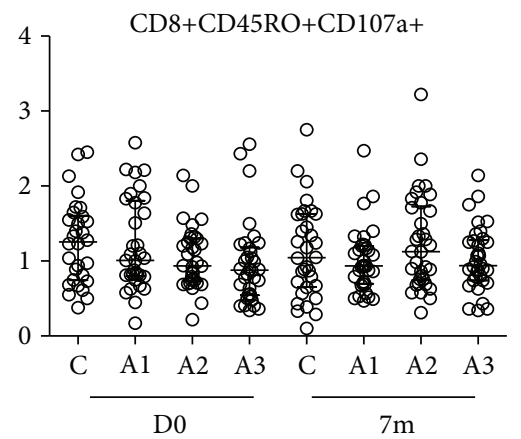

(j)

FiguRE 4: Comparison of fold increases in cytokine-producing and CD107a-expressing memory T cells between study groups. Fold increases in TNF- $\alpha$, IFN- $\gamma$, IL-2, and IL-10 cytokine production, and CD107a expression, by memory CD4+ (a-e) and CD8+ (f-j) T cells in response to recombinant HBsAg between healthy controls (c), the standard dose group (A1), the four doses group (A2), and the four double doses group (A3) were compared before in vivo vaccination on day 0 (D0) and month 7 (7m) after vaccination. Medians are represented by thick, wide horizontal bars; $25-75 \%$ interquartile ranges are represented by thin, narrow bars. All $p$ values $<0.05$ were considered statistically significant. “**” stands for $p<0.01$. 


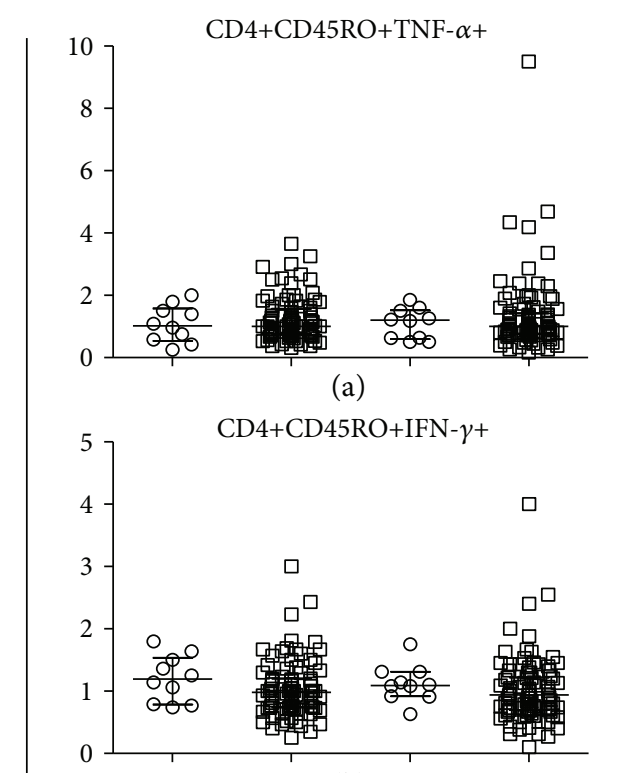

(b)

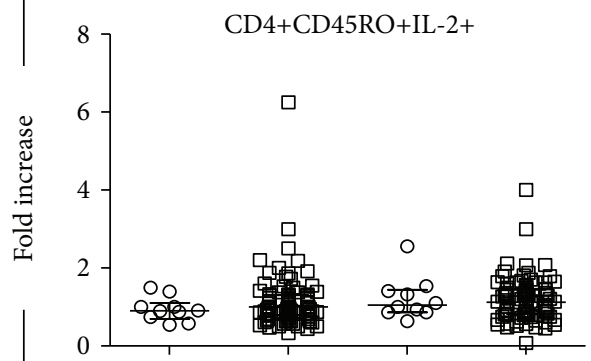

(c)

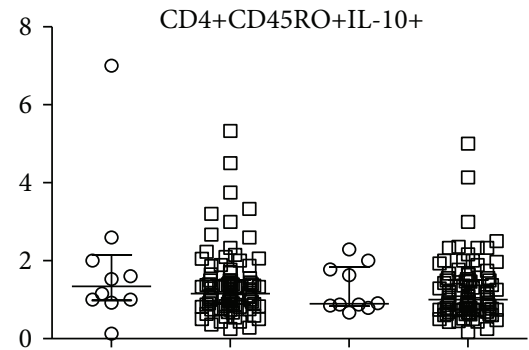

(d)

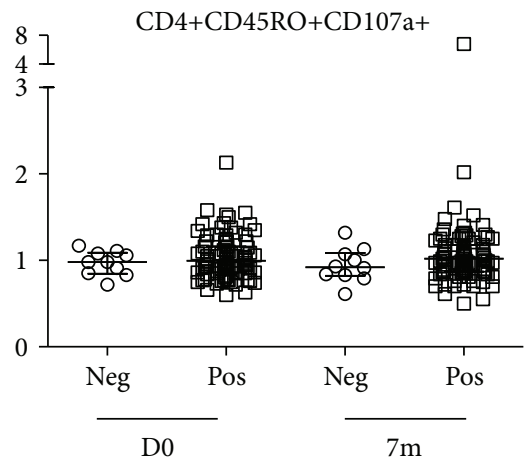

(e)

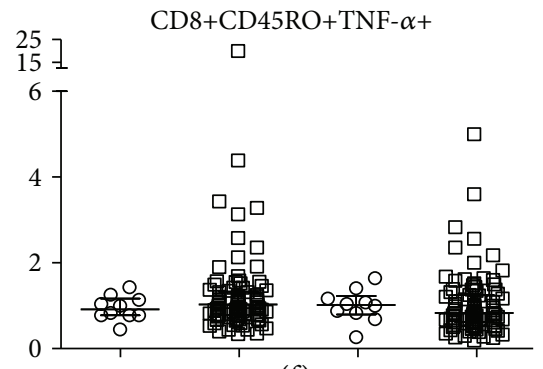

(f)

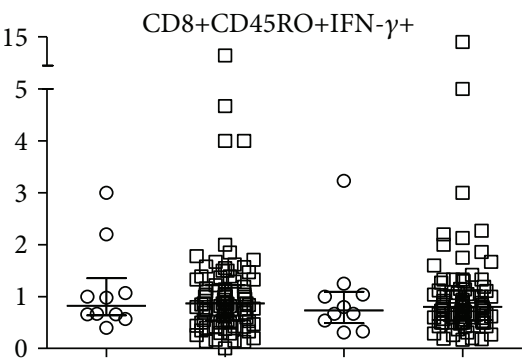

(g)

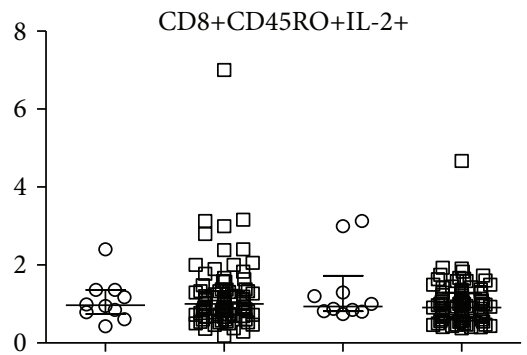

(h)

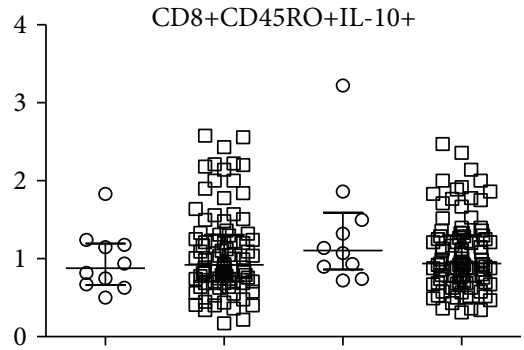

(i)

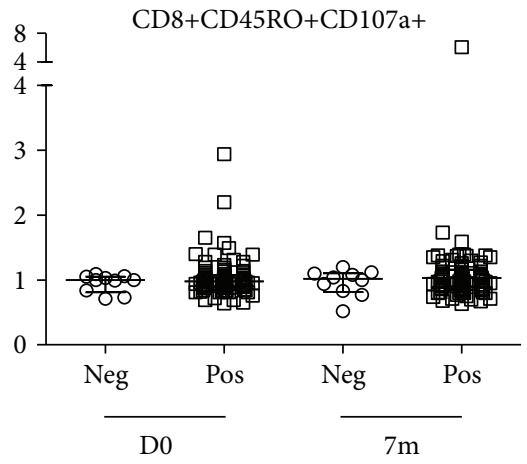

(j)

FIGURE 5: Fold increases in cytokine-producing and CD107a-expressing memory $\mathrm{T}$ cells between groups with regard to serological responsiveness to the vaccine. Fold increases in TNF- $\alpha$, IFN- $\gamma$, IL-2, and IL-10 production, and CD107a expression, by memory CD4+ (a) and $\mathrm{CD} 8+(\mathrm{b}) \mathrm{T}$ cells in response to recombinant HBsAg between seronegative (Neg) and seropositive (Pos) individuals among all the HIV+ participants were compared before in vivo vaccination on day 0 (D0) and month $7(7 \mathrm{~m})$ after vaccination. Medians are represented by thick, wide horizontal bars; $25-75 \%$ interquartile ranges are represented by thin, narrow bars. 
CD4+TNF- $\alpha+$
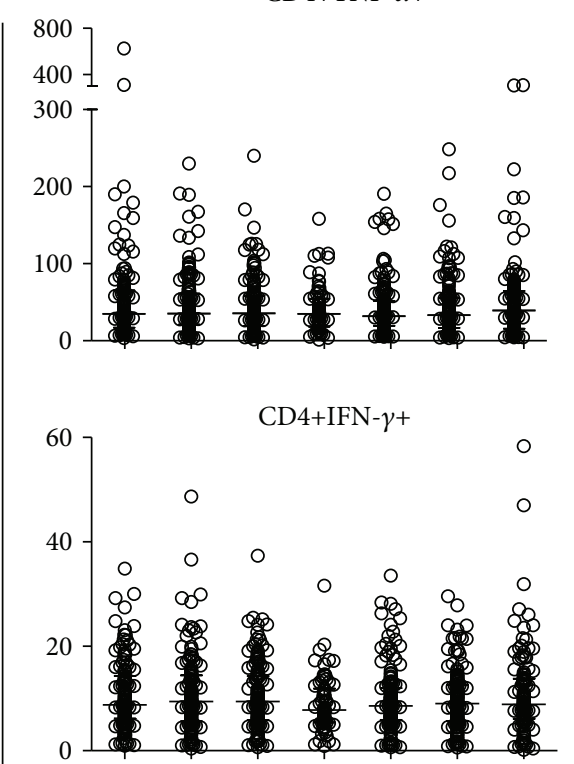

CD4+IL-2+
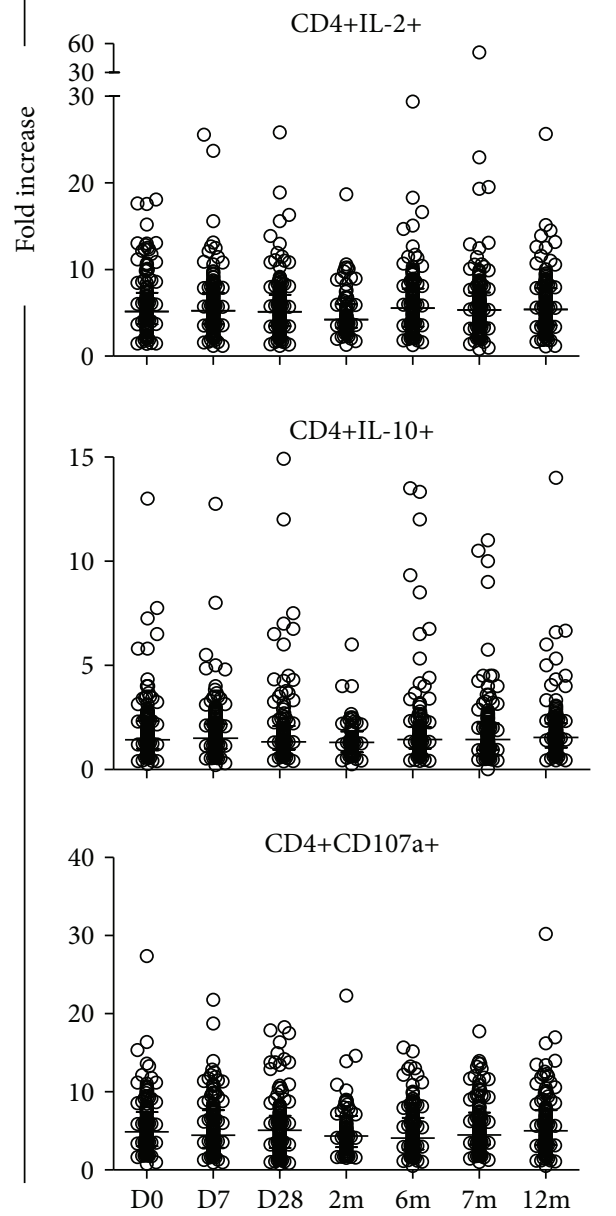

(a)
CD8+TNF- $\alpha+$
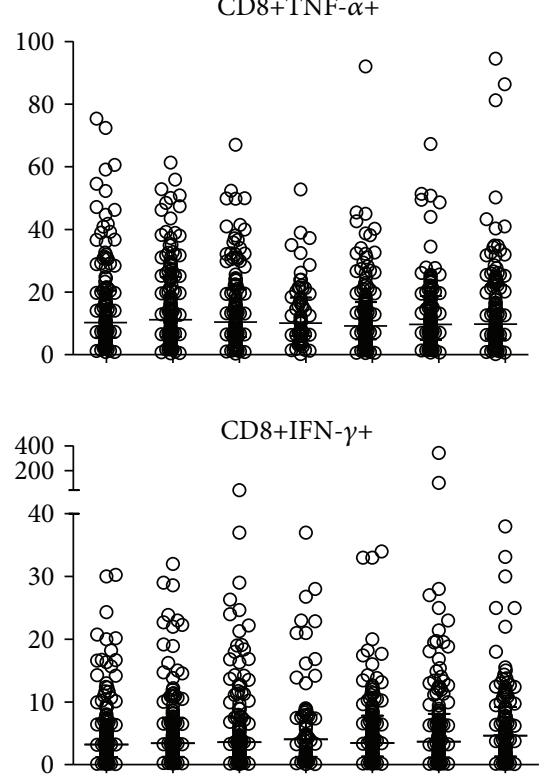

CD8+IL-2+

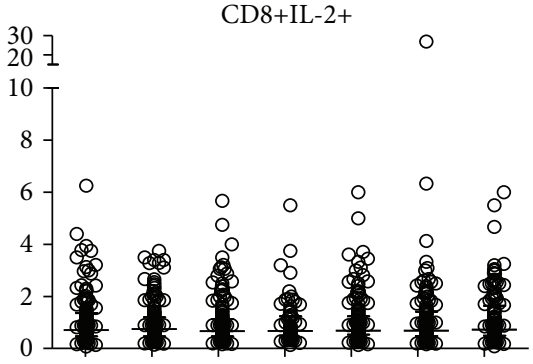

CD8+IL-10+
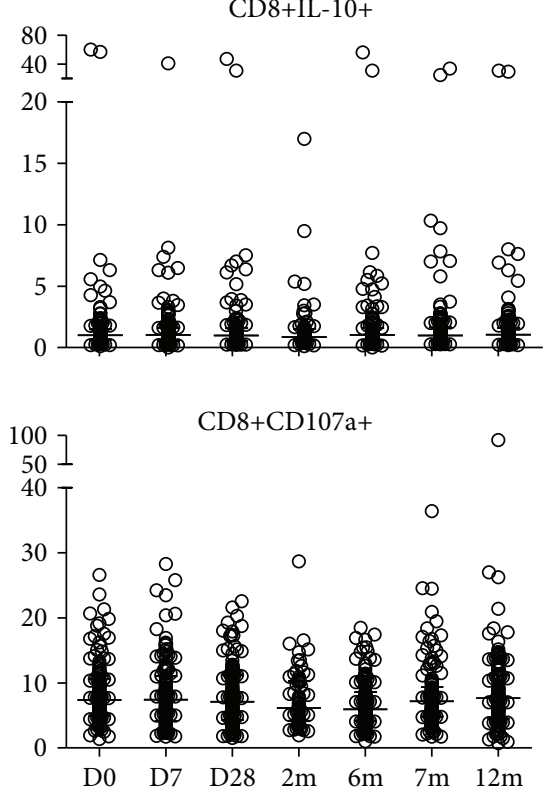

(b)

FIGURE 6: Fold increases in cytokine-producing and CD107a-expressing T cells in response to PHA stimulation. Fold increases in TNF- $\alpha$, IFN- $\gamma$, IL-2, and IL-10 cytokine production, and CD107a expression, by CD4+ (a) and CD8+ (b) T cells in response to PHA stimulation by all participants, compared with regard to before in vivo vaccination on day 0 (D0) and at day 7 (D7), day 28 (D28), month 6 (6m), month $7(7 \mathrm{~m})$, and month $12(12 \mathrm{~m})$ after vaccination. There were no statistical differences in the responses between visits. Medians are represented by thick, wide horizontal bars; $25-75 \%$ interquartile ranges are represented by thin, narrow bars. 
study in all the three HIV+ groups. This was not because of $\mathrm{T}$ cell defects or technical problem during the assays since $\mathrm{T}$ cells from all the participants produced cytokines in response to PHA stimulation, demonstrating the functional activity of the cryopreserved PBMCs. However, the results showed an increase in the TNF- $\alpha$-producing total and memory $\mathrm{CD} 4+\mathrm{T}$ cells at $7 \mathrm{~m}$ after vaccination in healthy controls compared to the HIV+ group, which received the same vaccination regimen (standard dose group). TNF- $\alpha$ has a direct effect on the proliferation of HBV-specific CTLs [36]. Upregulation of TNF- $\alpha$ of HBV-specific CTL abrogates gene expression and replication of HBV without killing infected hepatocytes [29, 37]. TNF- $\alpha$ also plays an important role in the inhibition of HBV-specific regulatory $T$ cell-suppressive function [38]. Higher production of TNF- $\alpha$ of HBV-specific CD4+ T cells after vaccination in healthy individuals suggests that at the standard vaccination regimen, they might achieve better control of $\mathrm{HBV}$ replication than do HIV+ individuals.

We also found an increase in HBsAg-specific IL-2producing memory $\mathrm{CD} 4+\mathrm{T}$ cells at $7 \mathrm{~m}$ after vaccination in the healthy control group. IL-2 has an effect on many immune cell types, especially lymphocytes for their differentiation and proliferation $[39,40]$. IL-2 secretion by memory CD4+ T cells is essential for B cell differentiation into IgGproducing plasma cells [41]. In general, vaccination with protein antigens in humans induces antigen-specific $\mathrm{T}$ cells to produce IL-2 more dominantly than do other cytokines $[42,43]$. The increase in IL-2 production in the healthy control group would be beneficial to these individuals against HBV infection. However, comparison of the IL-2-producing memory CD4+ T cells between all four groups at $7 \mathrm{~m}$ after vaccination, which was the peak of the response in the healthy controls, did not show any statistical difference. In addition, no significant increases in the cytokine-producing $\mathrm{T}$ cells or memory $\mathrm{T}$ cells were observed at all the time points during the investigation in the HIV+ groups. This might be the result of little increases in these HBV-specific cells. Whether using HBsAg-derived peptide pools may improve the sensitivity of the assay will be of great interest. No statistical differences in the frequencies of polyfunctional $\mathrm{T}$ cells in response to recombinant HBsAg between healthy controls and HIV+ groups were found (data not shown). This might be due to invigorated responses observed in our study. It should be noted that the absolute CD4 $\mathrm{T}$ cell counts of the HIV+ groups in our study and their viral loads were in good levels. All of them were also receiving ART. This could be a reason that no profound differences were observed in this study. Furthermore, the HBV vaccine used in this study was highly immunogenic in our populations as reflected by the high seroconversion rate in all the three HIV+ study groups [18]. The percentage of serological responders to HBV vaccination in HIV+ adults receiving the standard vaccination regimen was almost as high as that achieved in non-HIV healthy adults, in addition to much higher seroconversion rate than that reported by other studies [13, 19, 44, 45]. Such effective vaccine might induce CMI responses to a nearly comparable level in all groups.
The correlation between cellular and humoral immunity in response to $\mathrm{HBV}$ vaccination is still controversial. We did not find any differences in cytokine production between serological responders and nonresponders among HIV+ individuals. Our results were similar to those reported in healthy individuals [46]. Nevertheless, the production of cytokines observed in serological nonresponders in our and other studies [46] may shed light on the induction of specific cellular immunity to control HBV infection in this population. This issue warrants further investigation.

\section{Conclusion}

This study suggests that the standard HBV vaccination schedule induces the TNF- $\alpha$ - and IL-2-producing CD4+ T cells at $7 \mathrm{~m}$ after vaccination in healthy individuals, but that only the TNF- $\alpha$-producing CD4+ T cells were better than those of the HIV+ individuals who received the same vaccination regimen. Therefore, increased doses and/or frequencies may be beneficial for the HIV+ populations. Although further investigations are needed in order to explore the mechanisms that may contribute to protective CMI, the information from this study may provide valuable perception for future vaccine design to improve cellular immune responses to HBV vaccination for HIV+ populations.

\section{Disclosure}

The funder had no role in study design, data collection and interpretation, or the decision to submit the work for publication.

\section{Conflicts of Interest}

The authors declare that they have no conflicts of interest.

\section{Acknowledgments}

This work was supported by the Research University Program of Chiang Mai University under Thailand's Office of the Higher Education Commission. The authors express their gratitude to the study participants and thank Sasanee Teinkantes, Hataigan Jira, Kritsadee Rattanathammethee, and Narumon Techawong for their technical assistance, and Hi-Tech Outsourcing Services for editing the manuscript.

\section{Supplementary Materials}

Supplementary Table: the median and interquartile range of the percentages of cytokine-producing and CD107aexpressing memory CD4+ and CD8+ $\mathrm{T}$ cells in response to in vitro stimulation with $\mathrm{HBsAg}$ or medium alone (unstimulated). (Supplementary Materials)

\section{References}

[1] D. L. Thomas, R. O. Cannon, C. N. Shapiro, E. W. Hook 3rd, M. J. Alter, and T. C. Quinn, "Hepatitis C, hepatitis B, and human immunodeficiency virus infections among nonintravenous drug-using patients attending clinics for sexually 
transmitted diseases," The Journal of Infectious Diseases, vol. 169, no. 5, pp. 990-995, 1994.

[2] C. J. Hoffmann and C. L. Thio, "Clinical implications of HIV and hepatitis B co-infection in Asia and Africa," The Lancet Infectious Diseases, vol. 7, no. 6, pp. 402-409, 2007.

[3] A. P. Kourtis, M. Bulterys, D. J. Hu, and D. J. Jamieson, "HIV-HBV coinfection-a global challenge," The New England Journal of Medicine, vol. 366, no. 19, pp. 17491752, 2012.

[4] W. P. Law, C. J. Duncombe, A. Mahanontharit et al., "Impact of viral hepatitis co-infection on response to antiretroviral therapy and HIV disease progression in the HIV-NAT cohort," AIDS, vol. 18, no. 8, pp. 1169-1177, 2004.

[5] M. Chen, W. Wong, M. G. Law et al., "Hepatitis B and C co-infection in HIV patients from the TREAT Asia HIV observational database: analysis of risk factors and survival," PLoS One, vol. 11, no. 3, article e0150512, 2016.

[6] D. Salmon-Ceron, C. Lewden, P. Morlat et al., "Liver disease as a major cause of death among HIV infected patients: role of hepatitis C and B viruses and alcohol," Journal of Hepatology, vol. 42, no. 6, pp. 799-805, 2005.

[7] C. L. Thio, E. C. Seaberg, R. Skolasky Jr. et al., "HIV-1, hepatitis $\mathrm{B}$ virus, and risk of liver-related mortality in the Multicenter Cohort Study (MACS)," The Lancet, vol. 360, no. 9349, pp. 1921-1926, 2002.

[8] H. Masur, J. T. Brooks, C. A. Benson et al., "Prevention and treatment of opportunistic infections in HIV-infected adults and adolescents: updated guidelines from the Centers for Disease Control and Prevention, National Institutes of Health, and HIV Medicine Association of the Infectious Diseases Society of America," Clinical Infectious Diseases, vol. 58, no. 9, pp. 1308-1311, 2014.

[9] J. E. Kaplan, C. Benson, K. K. Holmes et al., "Guidelines for prevention and treatment of opportunistic infections in HIV-infected adults and adolescents: recommendations from CDC, the National Institutes of Health, and the HIV Medicine Association of the Infectious Diseases Society of America," MMWR Recommendations and reports, vol. 58, no. RR-4, pp. 1-207, 2009.

[10] A. M. Geretti, BHIVA Immunization Writing Committee, G. Brook et al., "Association guidelines for immunization of HIV-infected adults 2008," HIV Medicine, vol. 9, no. 10, pp. 795-848, 2008.

[11] O. Launay, D. van der Vliet, A. R. Rosenberg et al., "Safety and immunogenicity of 4 intramuscular double doses and 4 intradermal low doses vs standard hepatitis $\mathrm{B}$ vaccine regimen in adults with HIV-1: a randomized controlled trial," JAMA, vol. 305, no. 14, pp. 1432-1440, 2011.

[12] M. Bruguera, M. Cremades, R. Salinas, J. Costa, M. Grau, and J. Sans, "Impaired response to recombinant hepatitis B vaccine in HIV-infected persons," Journal of Clinical Gastroenterology, vol. 14, no. 1, pp. 27-30, 1992.

[13] I. P. Keet, G. van Doornum, A. Safary, and R. A. Coutinho, "Insufficient response to hepatitis B vaccination in HIVpositive homosexual men," AIDS, vol. 6, no. 5, pp. 509510, 1992.

[14] M. L. Landrum, K. Huppler Hullsiek, A. Ganesan et al., "Hepatitis B vaccine responses in a large U.S. military cohort of HIV-infected individuals: another benefit of HAART in those with preserved CD4 count," Vaccine, vol. 27, no. 34, pp. 4731-4738, 2009.
[15] I. J. Tsai, M. H. Chang, H. L. Chen et al., "Immunogenicity and reactogenicity of the combined hepatitis $\mathrm{A}$ and $\mathrm{B}$ vaccine in young adults," Vaccine, vol. 19, no. 4-5, pp. 437-441, 2000.

[16] M. Bruguera, J. M. Bayas, A. Vilella et al., "Immunogenicity and reactogenicity of a combined hepatitis $\mathrm{A}$ and $\mathrm{B}$ vaccine in young adults," Vaccine, vol. 14, no. 15, pp. 1407-1411, 1996.

[17] M. O. Fonseca, L. W. Pang, N. de Paula Cavalheiro, A. A. Barone, and M. Heloisa Lopes, "Randomized trial of recombinant hepatitis B vaccine in HIV-infected adult patients comparing a standard dose to a double dose," Vaccine, vol. 23, no. 22, pp. 2902-2908, 2005.

[18] K. Chaiklang, J. Wipasa, R. Chaiwarith, J. Praparattanapan, and K. Supparatpinyo, "Comparison of immunogenicity and safety of four doses and four double doses vs. standard doses of hepatitis B vaccination in HIV-infected adults: a randomized, controlled trial," PLoS One, vol. 8, no. 11, article e80409, 2013.

[19] D. Rey, V. Krantz, M. Partisani et al., "Increasing the number of hepatitis B vaccine injections augments anti-HBs response rate in HIV-infected patients. Effects on HIV-1 viral load," Vaccine, vol. 18, no. 13, pp. 1161-1165, 2000.

[20] M. Cruciani, C. Mengoli, G. Serpelloni et al., "Serologic response to hepatitis $\mathrm{B}$ vaccine with high dose and increasing number of injections in HIV infected adult patients," Vaccine, vol. 27, no. 1, pp. 17-22, 2009.

[21] B. Rehermann and M. Nascimbeni, "Immunology of hepatitis B virus and hepatitis C virus infection," Nature Reviews Immunology, vol. 5, no. 3, pp. 215-229, 2005.

[22] C. Boni, P. Fisicaro, C. Valdatta et al., "Characterization of hepatitis B virus (HBV)-specific T-cell dysfunction in chronic HBV infection," Journal of Virology, vol. 81, no. 8, pp. 42154225, 2007.

[23] C. Ferrari, A. Penna, A. Bertoletti et al., "Cellular immune response to hepatitis $B$ virus-encoded antigens in acute and chronic hepatitis B virus infection," The Journal of Immunology, vol. 145, no. 10, pp. 3442-3449, 1990.

[24] M. -C. Jung, U. Spengler, W. Schraut et al., "Hepatitis B virus antigen-specific T-cell activation in patients with acute and chronic hepatitis B," Journal of Hepatology, vol. 13, no. 3, pp. 310-317, 1991.

[25] C. Ferrari, A. Bertoletti, A. Penna et al., "Identification of immunodominant $\mathrm{T}$ cell epitopes of the hepatitis $\mathrm{B}$ virus nucleocapsid antigen," The Journal of Clinical Investigation, vol. 88, no. 1, pp. 214-222, 1991.

[26] European Association For The Study Of The Liver, "EASL clinical practice guidelines: management of chronic hepatitis B virus infection," Journal of Hepatology, vol. 57, no. 1, pp. 167-185, 2012.

[27] W. O. Böcher, S. Herzog-Hauff, J. Schlaak, K. H. Meyer zum Büschenfelde, and H. F. Löhr, "Kinetics of hepatitis B surface antigen-specific immune responses in acute and chronic hepatitis B or after HBs vaccination: stimulation of the in vitro antibody response by interferon gamma," Hepatology, vol. 29, no. 1, pp. 238-244, 1999.

[28] L. G. Guidotti and F. V. Chisari, "Noncytolytic control of viral infections by the innate and adaptive immune response," Annual Review of Immunology, vol. 19, no. 1, pp. 65-91, 2001.

[29] L. G. Guidotti, T. Ishikawa, M. V. Hobbs, B. Matzke, R. Schreiber, and F. V. Chisari, "Intracellular inactivation of the hepatitis B virus by cytotoxic T lymphocytes," Immunity, vol. 4 , no. 1, pp. 25-36, 1996. 
[30] L. G. Guidotti, R. Rochford, J. Chung, M. Shapiro, R. Purcell, and F. V. Chisari, "Viral clearance without destruction of infected cells during acute HBV infection," Science, vol. 284, no. 5415, pp. 825-829, 1999.

[31] J. Nystrom, K. Cardell, T. B. Bjornsdottir, A. Fryden, C. Hultgren, and M. Sallberg, "Improved cell mediated immune responses after successful re-vaccination of nonresponders to the hepatitis $B$ virus surface antigen (HBsAg) vaccine using the combined hepatitis A and B vaccine," Vaccine, vol. 26, no. 47, pp. 5967-5972, 2008.

[32] H. Saffar, M. J. Saffar, A. Ajami, A. R. Khalilian, K. ShamsEsfandabad, and A. M. Mirabi, "Long-term T-cell-mediated immunologic memory to hepatitis B vaccine in young adults following neonatal vaccination," Hepatitis Monthly, vol. 14, no. 9, article e22223, 2014.

[33] J. Wipasa, L. Okell, S. Sakkhachornphop et al., "Short-lived IFN- $\gamma$ effector responses, but long-lived IL-10 memory responses, to malaria in an area of low malaria endemicity," PLoS Pathogens, vol. 7, no. 2, article e1001281, 2011.

[34] K. Chawansuntati, N. Chotirosniramit, P. Sugandhavesa et al., "Low expression of activation marker CD69 and chemokine receptors CCR5 and CXCR3 on memory T cells after 2009 $\mathrm{H}_{1} \mathrm{~N}_{1}$ influenza $A$ antigen stimulation in vitro following H1N1 vaccination of HIV-infected individuals," Human Vaccines \& Immunotherapeutics, vol. 11, no. 9, pp. 22532265, 2015.

[35] E. E. Mast, C. M. Weinbaum, A. E. Fiore et al., "A comprehensive immunization strategy to eliminate transmission of hepatitis B virus infection in the United States: recommendations of the Advisory Committee on Immunization Practices (ACIP) Part II: immunization of adults," MMWR Recommendations and Reports, vol. 55, no. RR-16, pp. 1-33, 2006.

[36] S. Kasahara, K. Ando, K. Saito et al., "Lack of tumor necrosis factor alpha induces impaired proliferation of hepatitis B virus-specific cytotoxic T lymphocytes," Journal of Virology, vol. 77, no. 4, pp. 2469-2476, 2003.

[37] L. G. Guidotti, K. Ando, M. V. Hobbs et al., "Cytotoxic T lymphocytes inhibit hepatitis B virus gene expression by a noncytolytic mechanism in transgenic mice," Proceedings of the National Academy of Sciences of the United States of America, vol. 91, no. 9, pp. 3764-3768, 1994.

[38] J. N. Stoop, A. M. Woltman, P. J. Biesta et al., “Tumor necrosis factor alpha inhibits the suppressive effect of regulatory $\mathrm{T}$ cells on the hepatitis B virus-specific immune response," Hepatology, vol. 46, no. 3, pp. 699-705, 2007.

[39] O. Boyman and J. Sprent, "The role of interleukin-2 during homeostasis and activation of the immune system," Nature Reviews Immunology, vol. 12, no. 3, pp. 180-190, 2012.

[40] S. Gaffen and K. Liu, "Overview of interleukin-2 function, production and clinical applications," Cytokine, vol. 28, no. 3, pp. 109-123, 2004.

[41] N. H. Litjens, M. Huisman, D. Hijdra, B. M. Lambrecht, K. J. Stittelaar, and M. G. Betjes, "IL-2 producing memory $\mathrm{CD} 4^{+}$ $\mathrm{T}$ lymphocytes are closely associated with the generation of IgG-secreting plasma cells," The Journal of Immunology, vol. 181, no. 5, pp. 3665-3673, 2008.

[42] S. C. De Rosa, F. X. Lu, J. Yu et al., "Vaccination in humans generates broad T cell cytokine responses," The Journal of Immunology, vol. 173, no. 9, pp. 5372-5380, 2004.

[43] A. A. Divekar, D. M. W. Zaiss, F. E.-H. Lee et al., "Protein vaccines induce uncommitted IL-2-secreting human and mouse CD4 T cells, whereas infections induce more IFN- $\gamma$ - secreting cells," The Journal of Immunology, vol. 176, no. 3, pp. 1465-1473, 2006.

[44] H. N. Kim, R. D. Harrington, S. E. Van Rompaey, and M. M. Kitahata, "Independent clinical predictors of impaired response to hepatitis B vaccination in HIV-infected persons," International Journal of STD \& AIDS, vol. 19, no. 9, pp. 600604, 2008.

[45] S. C. Tayal and K. N. Sankar, "Impaired response to recombinant hepatitis B vaccine in asymptomatic HIV-infected individuals," AIDS, vol. 8, no. 4, pp. 558-559, 1994.

[46] L. Jarrosson, M. N. Kolopp-Sarda, P. Aguilar et al., "Most humoral non-responders to hepatitis B vaccines develop HBV-specific cellular immune responses," Vaccine, vol. 22, no. 27-28, pp. 3789-3796, 2004. 


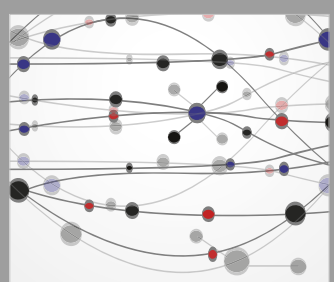

The Scientific World Journal
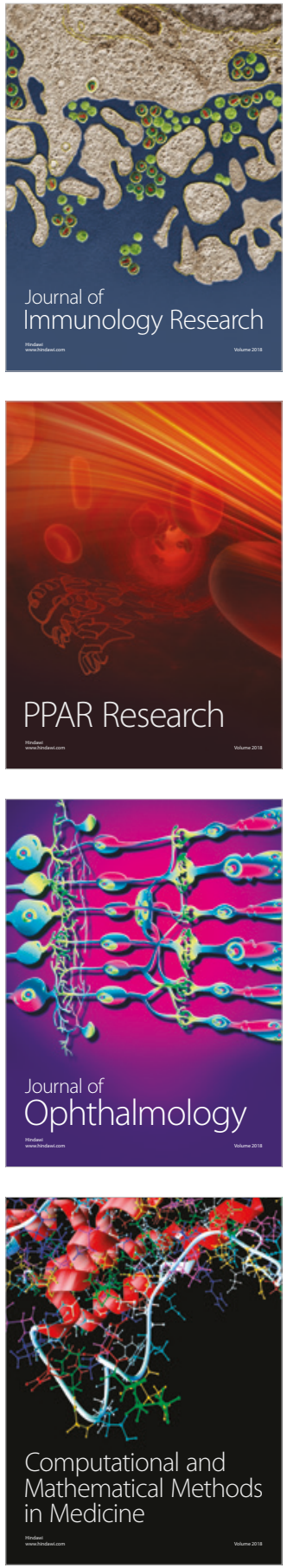

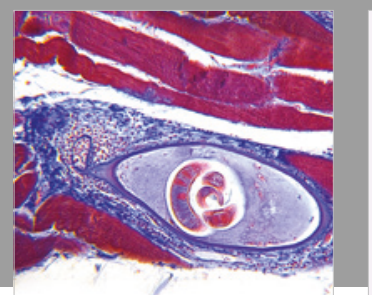

Gastroenterology Research and Practice

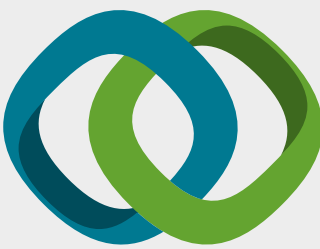

\section{Hindawi}

Submit your manuscripts at

www.hindawi.com
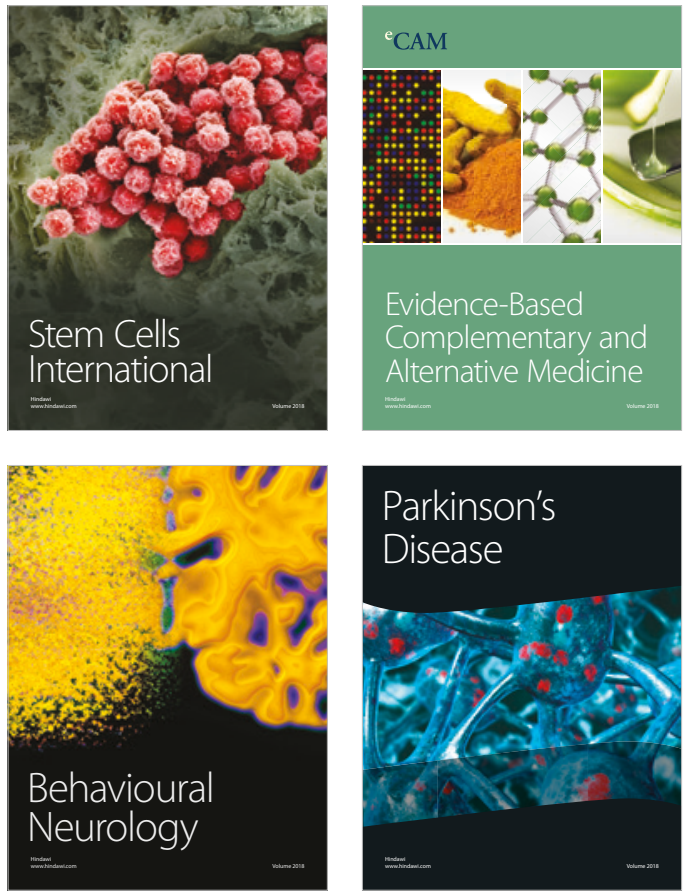

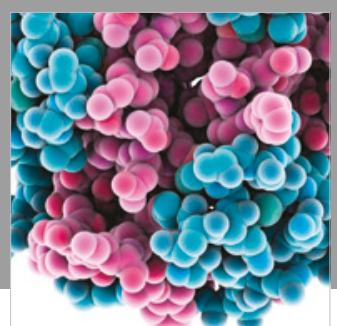

ournal of

Diabetes Research

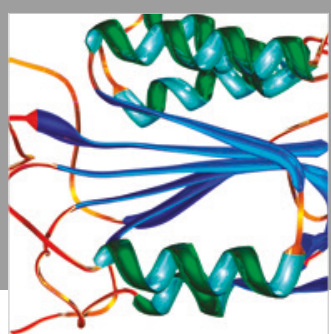

Disease Markers
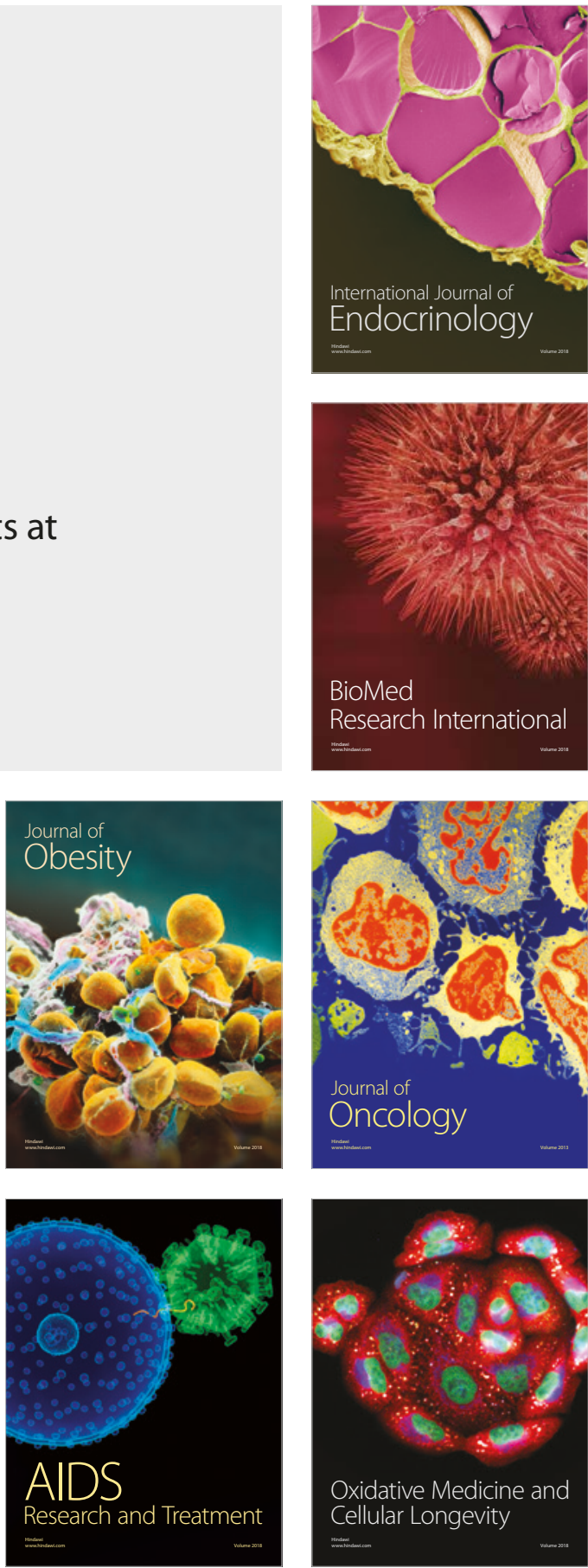